\title{
Pyrolysis and liquefaction of rice straw and computational modelling of fixed-bed reactor for heat distribution
}

\author{
Gokul Gopan, Lalhmingsanga Hauchhum*', Renjith Krishnan, Satyajit Pattanayak \\ Department of Mechanical Engineering, National Institute of Technology Mizoram, Aizawl 796012, India \\ Corresponding author: hlalhmingsang@gmail.com
}

\begin{abstract}
The quest for new eco-friendly energy resources dates back to three decades not because of the resources are being scarce but because of its capacity to mitigate the unfriendly environmental issues. The fossil fuel resources are formed over thousands of years of biochemical conversion, which is insufficient to feed the ever-growing need for energy usage. Moreover, their contribution to increasing pollution needs to be reduced. As this process is slow, alternate method of rapid fuel generation (thermo-chemical conversion) came into consideration that paves a more promising route in deriving bio-oil from biomass. Liquefaction is such technique of deriving bio-oil from biomass species that ensures high energy efficiency, low tar yield and lower operating temperature. It operates usually between the temperature of $523 \mathrm{~K}$ and $647 \mathrm{~K}$, and pressure of 4 to $22 \mathrm{MPa}$. This paper particularly highlights the derivation of bio-oil derived from rice straw biomass (UMA paddy straw) from the pyrolytic gas, followed by the computational modelling of fixed-bed combustion reactor using K-epsilon turbulence model displaying temperature gradient, pressure gradient profile and streamlines of fluid flow inside combustion reactor. Furthermore, pyrolysis and liquefaction are promising alternatives for enriched bio-oil production for simplicity compared to other thermochemical conversion processes.
\end{abstract}

Keywords: Bio-oil, pyrolysis, liquefaction, biomass, computational modelling, rice straw.

\section{INTRODUCTION}

Renewable energy source receives wide applause in terms of environmental-friendly concerns and reduction in adverse ecological impacts compared to fossil fuels. The energy demand is increasing with the rise in population and brings the vital need for alternate economical renewable sources into play. Wood and various other forms of naturally occurring biomass are considered to be the main renewable energy sources available for producing energy by combustion to produce heat, such as steam production and electricity generation (Bridgwater et al., 1999). Biomass is a clean source of energy having negligible content of sulphur, nitrogen and ash, and thus accounts for lower emission of $\mathrm{SO}_{2}, \mathrm{NO}_{x}$ (Zhang et al., 2007).

Syngas or producer gas is obtained through the gasification of biomass where fossil fuel based carbonaceous material or organic matter is converted in to $\mathrm{CO}, \mathrm{H}$ and $\mathrm{CO}_{2}$. Pyrolysis is the thermal degradation of organic mat- ter to derive bio-oil, pyrolysis oil or biomass pyrolysis oil. Pyrolysis is the technique of applying high heat to lignocellulosic materials in the absence of or little air. The process can produce charcoal, condensable organic liquids, non-condensable gases and other constituents (Demirbas, 1998). The bio-oil contains number of organic compounds that belong to alkanes, aromatic hydrocarbons, phenol derivatives and little amounts of ketones, esters, ethers, sugars, amines and alcohols with $\mathrm{H} / \mathrm{C}$ molar ratio higher than 1.5 (Wu et al., 2009). Another promising route of deriving bio-oil other than the above mentioned method is the direct liquefaction, where the solid biomass is converted directly to liquid fuel.

In this particular work, the biomass of paddy straw variety UMA collected from South India was made to undergo direct liquefaction whereby the pyrolytic product gas was converted to Bio-oil. This proved the better functionality of the liquefaction process utilised for producing bio-oil being the possible alternative for making bio derivatives. Computational fluid modelling (CFD) was 
found to be an effective and economical tool in simulating fluidized bed gasifiers in which governing equations for mass, momentum, energy and species transport are solved to obtain the spatial and temporal variation of parameters (Anil et al., 2015). Computational modelling simulations were used to help reduce the experimental efforts by allowing for verifications of several arrangements of a fluid flow management setup (Mousaad and Hamzeh, 2017). The computational modelling of fixedbed reactor is done in CFD Solver ANSYS FLUENT 14.5, where the fluid behaviour was studied using K-epsilon turbulence model for the transient turbulent flow. Kepsilon model was found to be giving better and realistic results compared to other flow models. Behaviours like Temperature gradient, density, pressure gradient etc. were studied. Furthermore, the bio-oil production from biomass can become a possible alternative to fossil fuels over years.

\section{MATERials AND METHOdS}

Here rice straw of variety UMA (specifically cultivated in Kerala, India) is used as biomass, to derive bio oil. At first, biomass is converted to pyrolytic gas by the process called pyrolysis and this gas is cooled by liquefaction process to get bio oil. The methodology for this paper is shown in Figure 1.

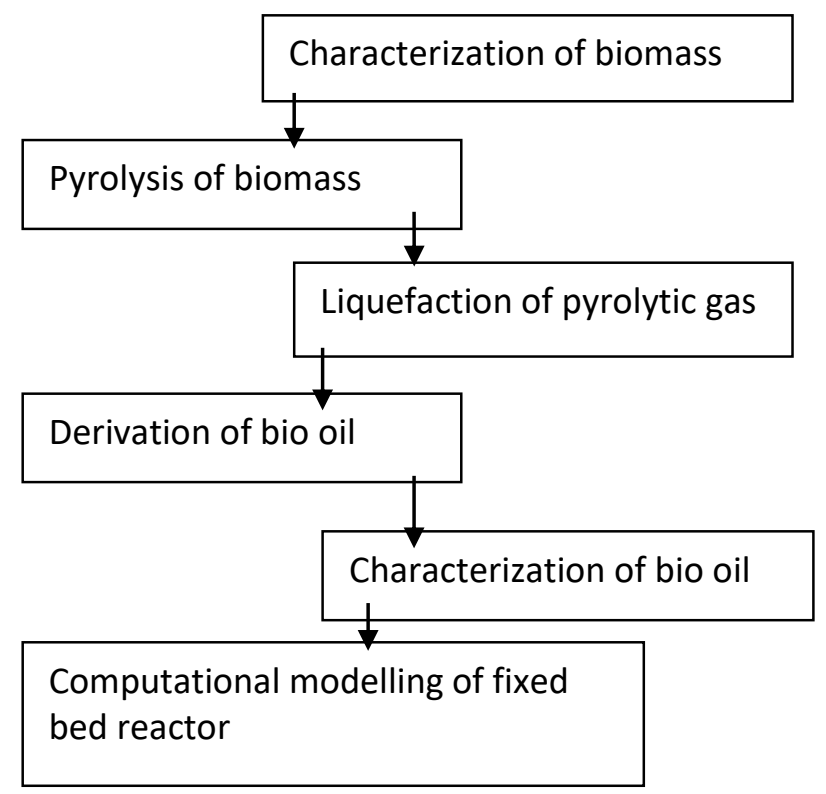

Figure 1: Methodology for the characterisation of biomass of rice straw UMA.

In characterisation of biomass, proximate analysis values and calorific value are found. All the experiments are done according to ASTM standards. After that biomass is fed to a combustion reactor for pyrolysis process and the pyrolytic gas after this process moves to a condenser for liquefaction. In this process, the biomass is
Table 1: Values for the characterization of rice straw.

\begin{tabular}{ll}
\hline Analysis & Codes \\
\hline Proximate analysis (\%) & \\
\hline MC & 15.48 \\
\hline VM & 5.69 \\
\hline AC & 12.58 \\
\hline FC & 66.25 \\
\hline HHV (MJ/ kg) & 17.3616 \\
\hline
\end{tabular}

Table 2: Rice straw oil parameters.

\begin{tabular}{llc}
\hline S.N. & Parameter & Value \\
\hline 1 & Density $\left(\mathrm{kg} / \mathrm{m}^{3}\right)$ & 0.908 \\
\hline 2 & Yield efficiency $(\%)$ & 5.924 \\
\hline 3 & Flash point $\left({ }^{\circ} \mathrm{C}\right)$ & 77 \\
\hline 4 & Fire point $\left({ }^{\circ} \mathrm{C}\right)$ & 82 \\
\hline
\end{tabular}

Table 3: Simulation parameters and other properties.

\begin{tabular}{lll}
\hline SI & Biomass & \\
\hline 1 & Material & Rice straw \\
\hline 2 & Particle size & $15 \mathrm{~cm}$ \\
\hline & Other & \\
\hline 4 & Outlet pressure & $1.72 \mathrm{bar}$ \\
\hline 5 & Inlet pressure & $2.72 \mathrm{bar}$ \\
\hline 6 & Time step size & 0.01 \\
\hline 7 & No: time steps & 2000 \\
\hline 8 & Maximum iterations per time step & 40
\end{tabular}

Table 4: Fixed-bed reactor temperature distribution.

\begin{tabular}{llc}
\hline Sl. & Temperature of reactor & ${ }^{\circ} \mathbf{C}$ \\
\hline 1 & Ash temperature & 54 \\
\hline 2 & Grate temperature & 78.5 \\
\hline 3 & Reactor bottom temperature & 91.4 \\
\hline 4 & Reactor temperature (mid-section) & 140.8 \\
\hline 5 & Gas outlet Temperature & 152.1 \\
\hline 6 & Pyrolysis zone temperature & 497.2 \\
\hline
\end{tabular}

totally converted to bio oil. The experimental setups for these processes are shown in Figure 2 . The yield efficiency (biomass to bio oil) is also calculated. The extracted bio oil is then heated to remove the moisture content of the oil. Then it is used for finding density, flash point and fire point.

The computational modelling of the fixed-bed reactor/combustion reactor is done in CFD solver ANSYS FLUENT 14.5. Simulation is carried out for 2D fixed-bed reactor as shown in Table 3 and Figure 3. The biomass is fed from the top as shown in Figure 2.

\section{RESUlTS AND DISCUSSION}

\section{Characterisation of biomass}

The values of moisture content $(\mathrm{MC})$, ash content 


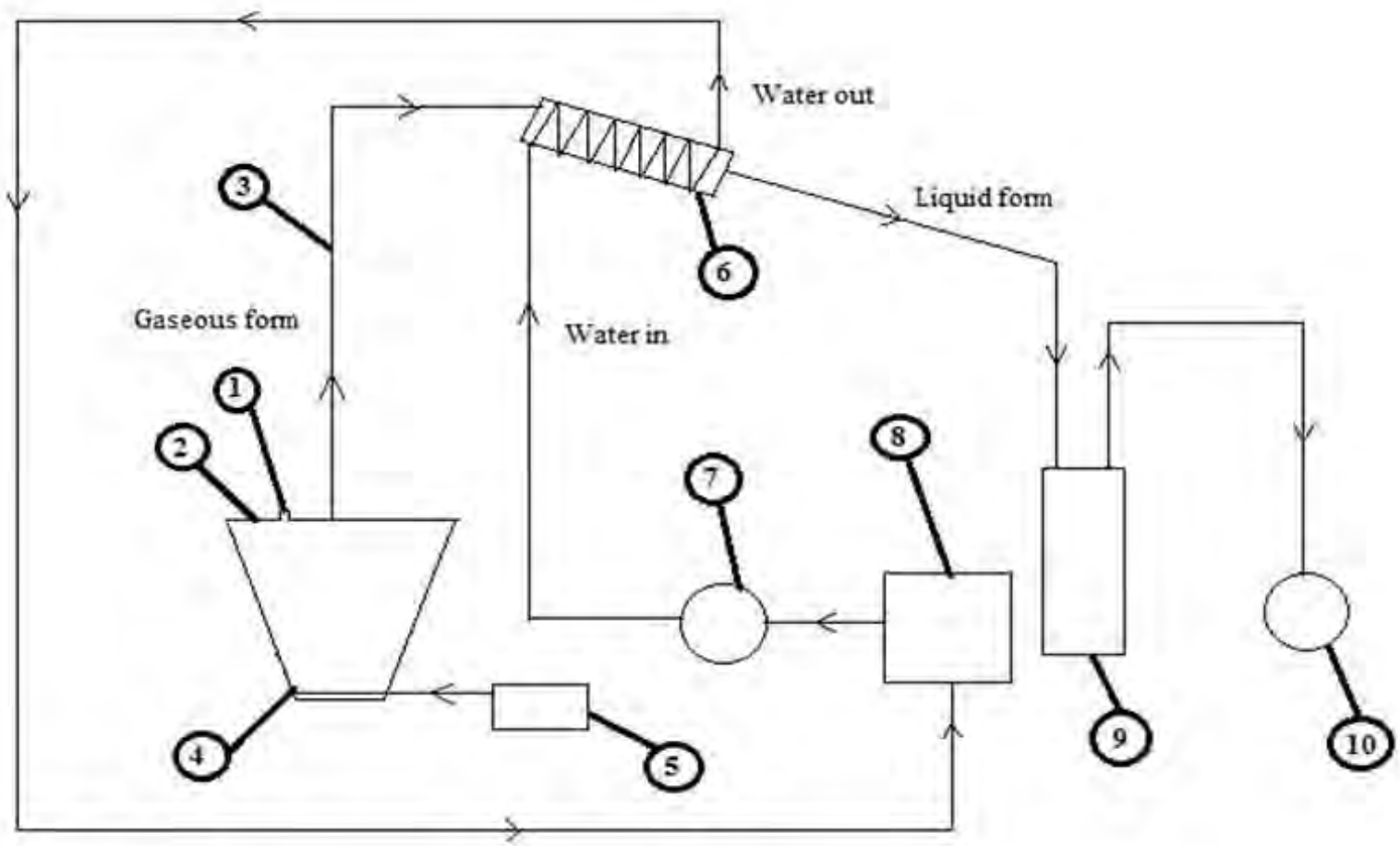

Figure 2: Experimental setup for extracting bio-oil: 1) biomass feed; 2) combustion reactor; 3) tube; 4) grate; 5) burner; 6) condenser; 7) aqua pump; 8) water tank; 9) beaker; 10) vacuum pump.

Figure 3: Fixed-bed reactor sketch done in ANSYS 14.5; H53=5cm (biomass feed), $\mathrm{H} 54=3 \mathrm{~cm}$ (gas outlet), V56=28cm (reactor length), H55=4.5cm (grate).

Figure 4: Temperature distribution over the reactor.

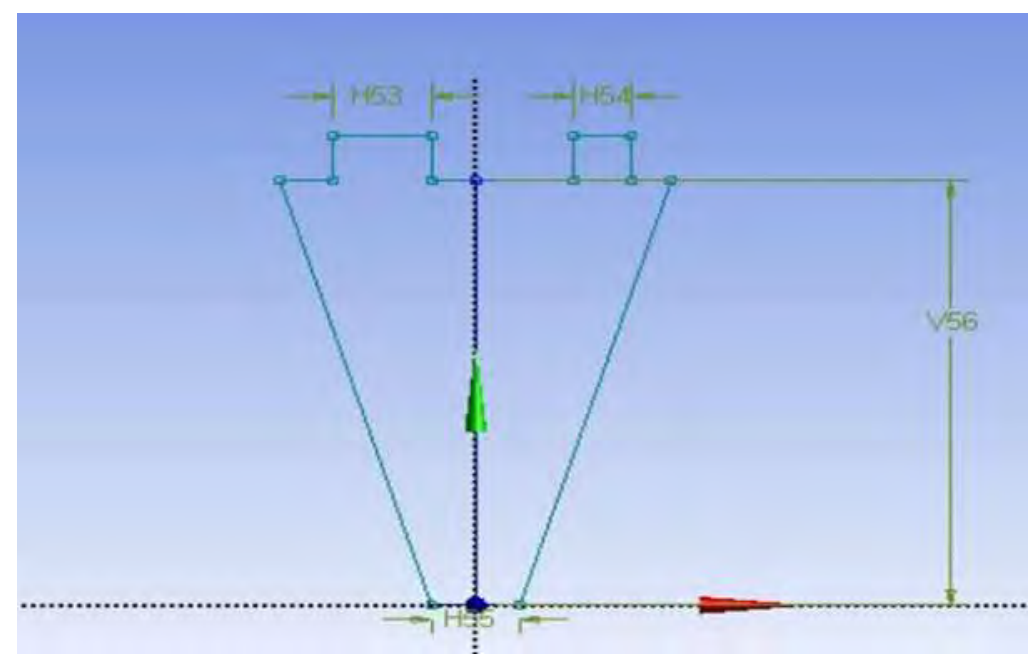

$\mathrm{X}$-axis- Chamber domain length $(\mathrm{cm})$

Y-axis- Chamber Temperature $\left({ }^{\circ} \mathrm{C}\right)$

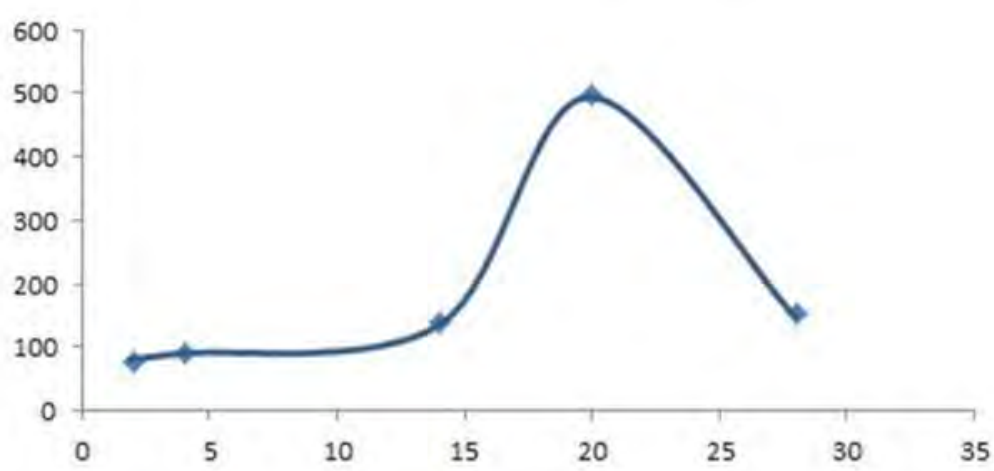




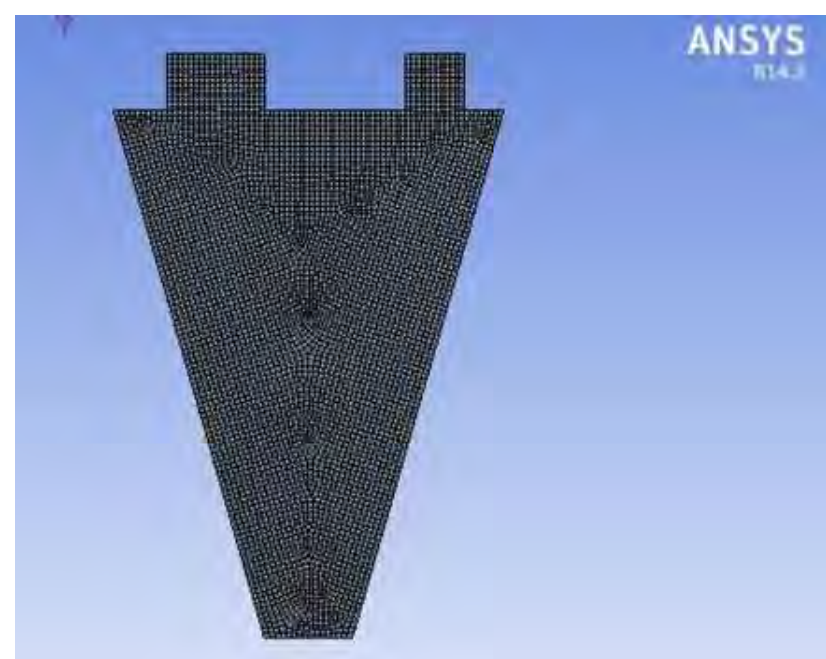

Figure 5: Meshing and Mesh refinement.

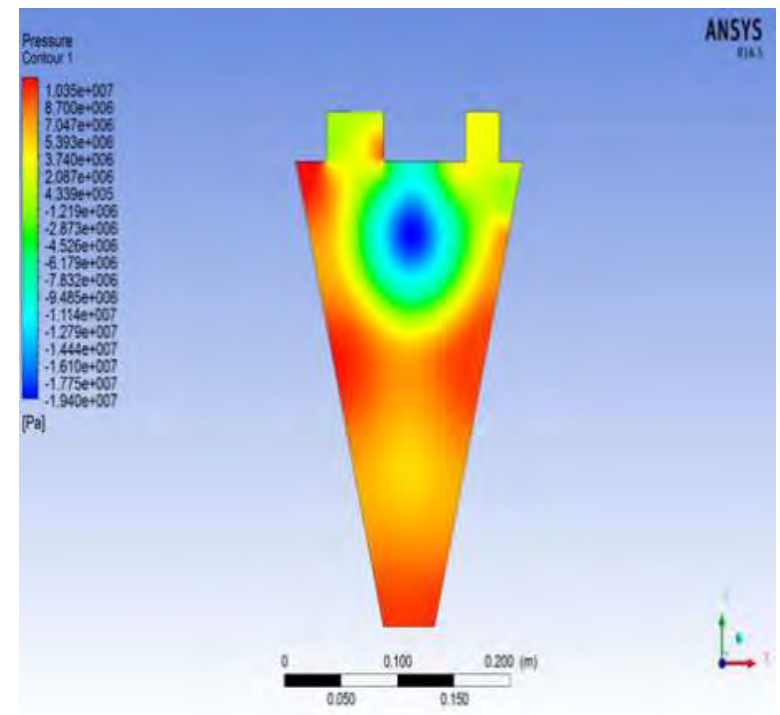

Figure 7: Varying temperature gradient over all domain.

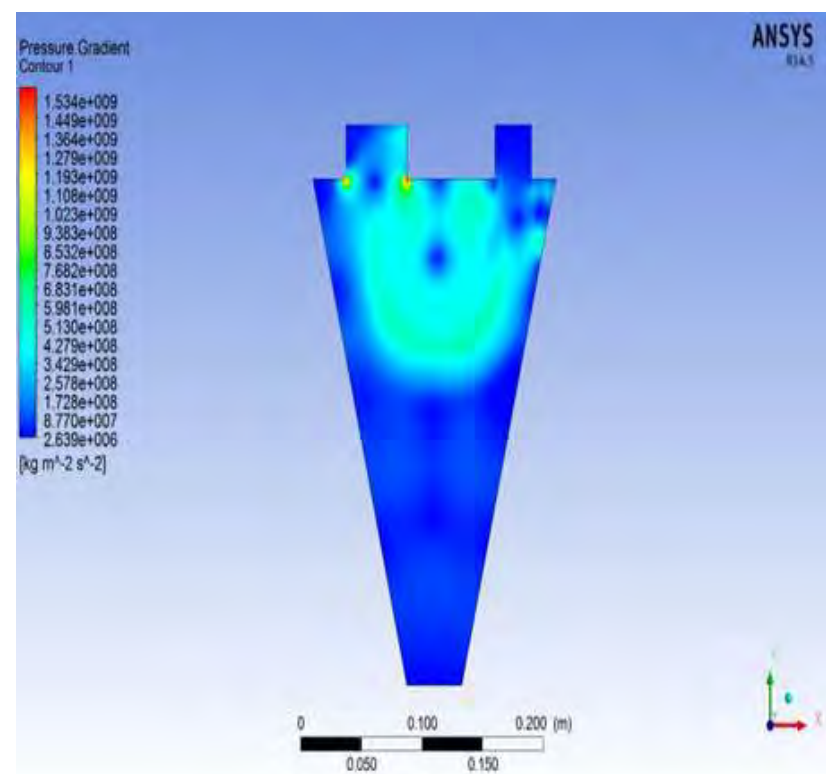

Figure 9: Varying pressure gradient over all domain.

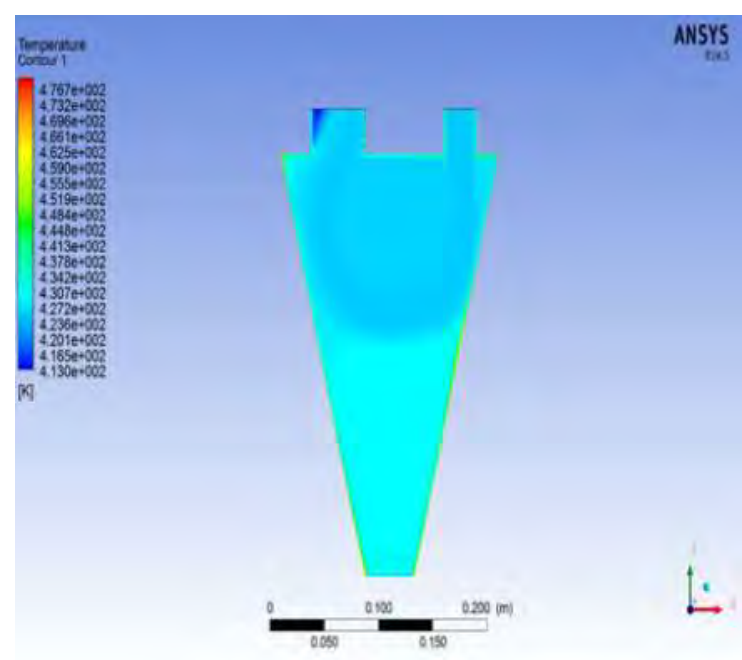

Figure 6: Varying temperature over all domain.

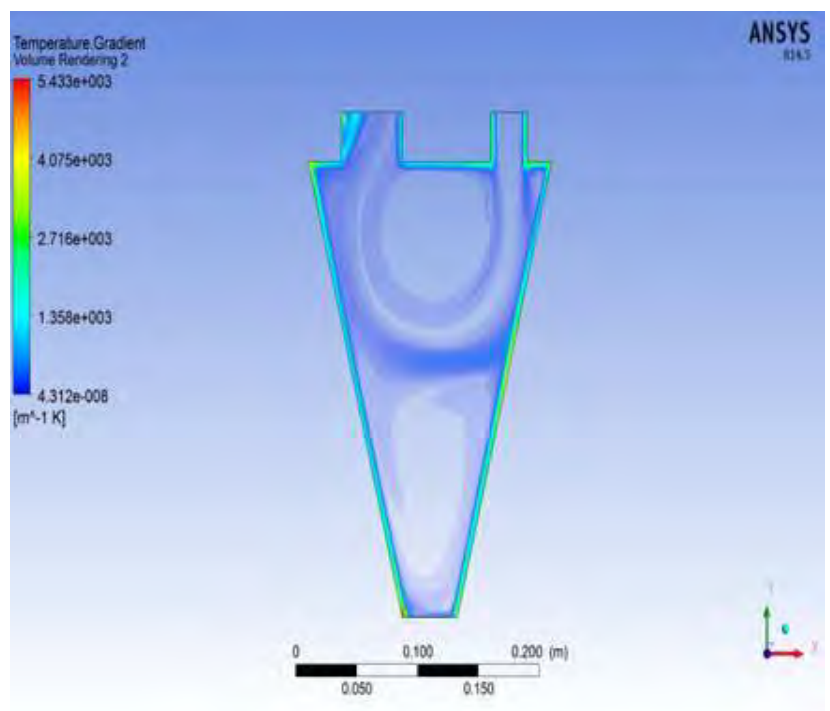

Figure 8: Varying pressure over all domain.

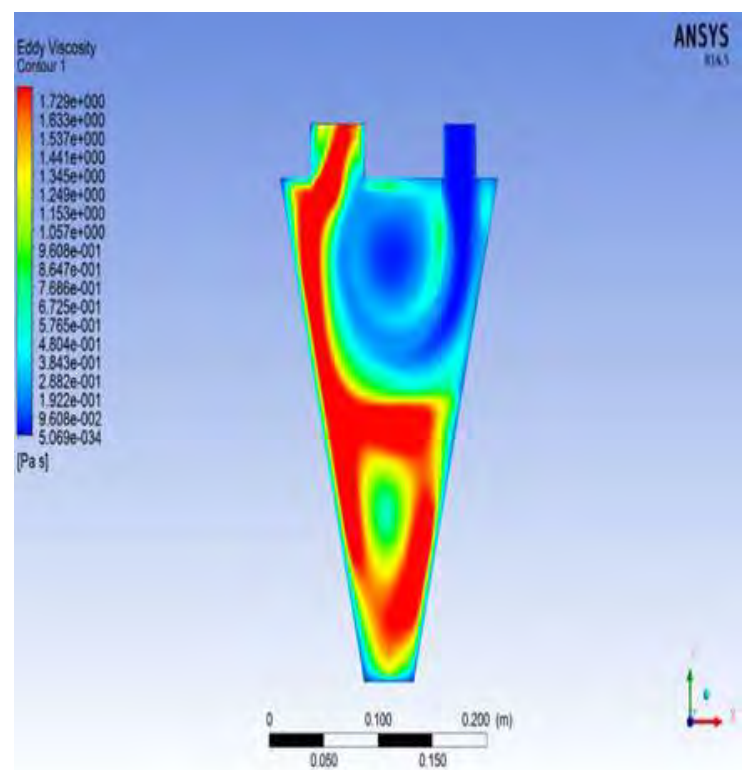

Figure 10: Varying eddy viscosity over all domain. 


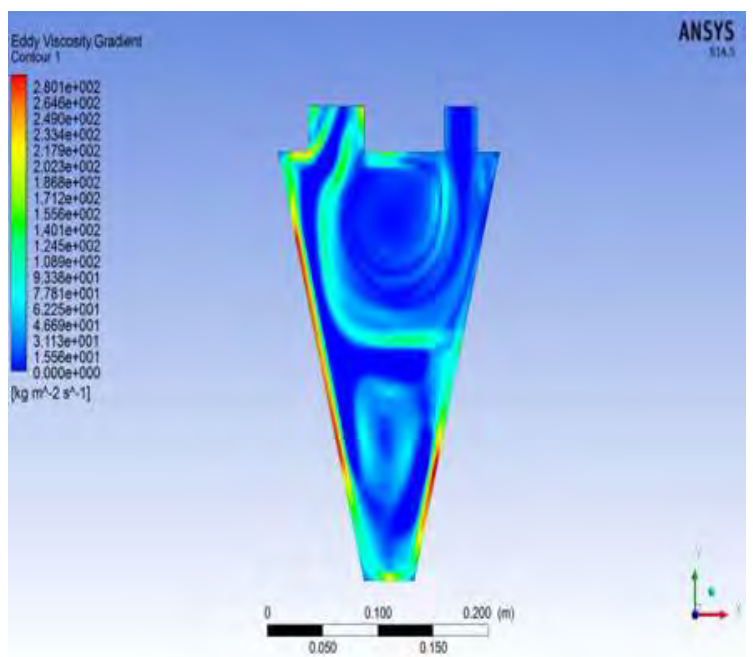

Figure 11: Varying eddy viscosity gradient over all domain.

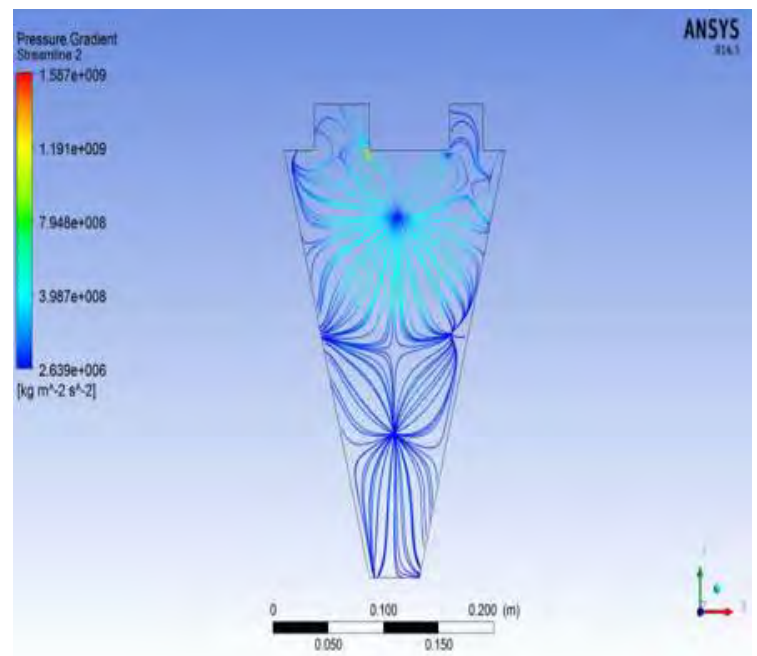

Figure 13: Streamlines of pressure gradient at all domain.

(AC), volatile matter (VM) and higher heating value (HHV) are found out by ASTM standards (ASTM International; 2015, 2013). The value of fixed carbon (FC) is found by equation 1 .

$$
F C=100-(M C+A C+V M)
$$

As the moisture content is somewhat high, then also it shows a promising calorific value. So if we reduce the moisture content, the calorific value will also increase.

\section{Derivation of bio oil and its characterization}

After extracting the bio oil from rice straw, the density, yield efficiency, flash point and fire point are calculated. By extracting $1 \mathrm{~kg}$ of rice straw, it gives $63 \mathrm{ml}$ bio oil which is having mass $59.24 \mathrm{~g}$. So that it can be con-

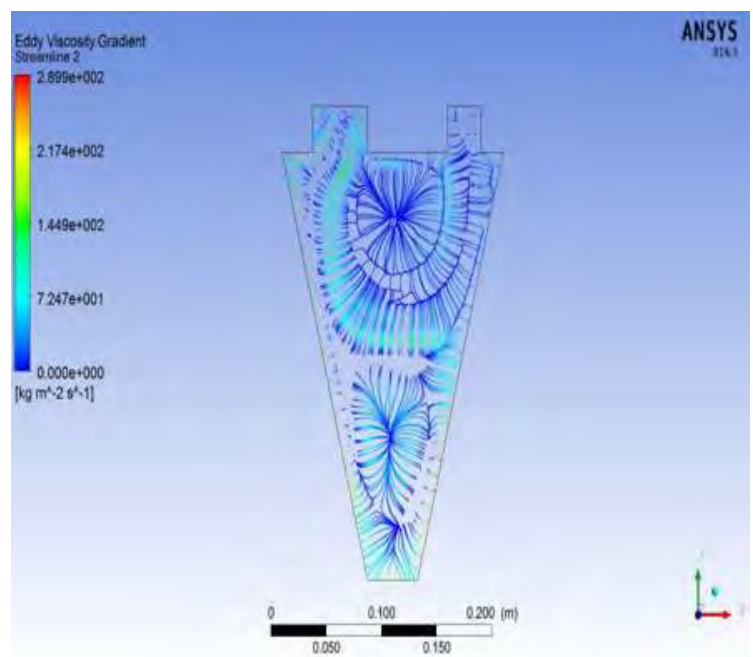

Figure 12: Streamlines at 500 points showing varying viscosity gradient over all domain.

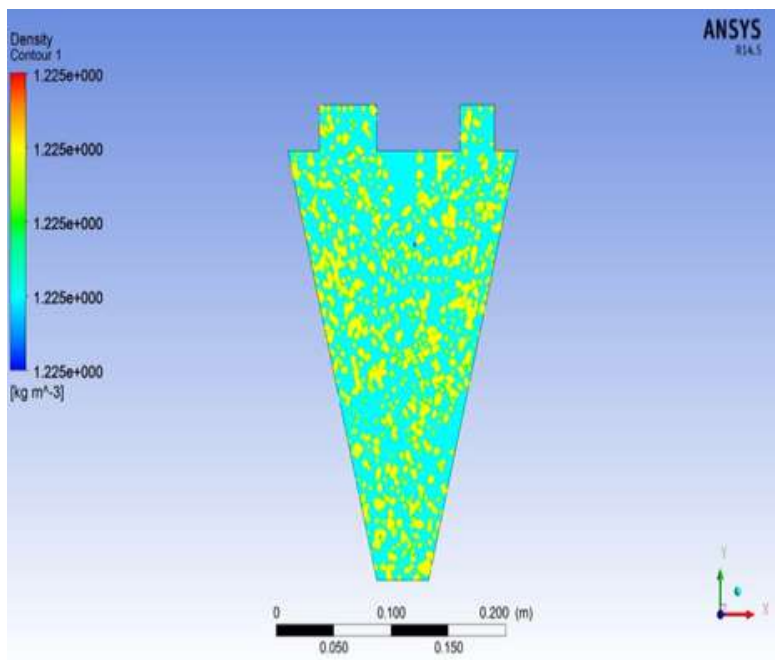

Figure 14: Variation of density over 150 points over all domain in forward and backward direction.

cluded that, for extracting 1 litre of bio oil, it needs 15.87 $\mathrm{kg}$ of rice straw. The values of the parameters of oil are mentioned in Table 2.

\section{Computational modeling of fixed-bed reactor}

The temperature distribution over the fixed-bed reactor is given in Table 4, and graphically plotted as shown in Figure 4.

The temperature distribution over the reactor shows that the maximum temperature attained in the pyrolysis region is $497.2^{\circ} \mathrm{C}$, the backflow temperature at the exit is found to be $140^{\circ} \mathrm{C}$. Between the reactor zones of 15 to $28 \mathrm{~cm}$, the maximum pyrolytic temperature observed. The 2D profile of the reactor is created in ANSYS 14.5, Meshing of the profile is done, and mesh refinement is provided on proximity and curvature of the $2 \mathrm{D}$ profile to 
get more accurate convergence in the FLUENT solver. Effect of gravity is considered only along the y axis (-9.81 $\left.\mathrm{m} / \mathrm{s}^{2}\right)$. The general setup proceeded with solver pressure based and time taken as transient. The viscous model selected is K-epsilon, with realisable, scalable wall function, energy equation is also added. The boundary conditions are applied as in Table 1 and Table 3. The solution method selected is simple scheme. Solution initialisation is done for hybrid initialisation. No of time steps selected is 2000 with a time step size of 0.01 . The maximum iterations/ time step is 40 and reporting interval is 10 . The results obtained are displayed.

Figure 6 shows the varying temperature over all domains, it can be inferred that the maximum temperature zone is confined towards the top region of the reactor $(15-28 \mathrm{~cm})$. The average temperature over the entire domain accounts to $184^{\circ} \mathrm{C}$. The recirculation of gas on the contour is seen as circle over the top region of reactor. In Figures 8 and 9, the maximum pressure variation over all domains is clearly depicted. The maximum pressure at inlet and outlet accounts to 2.72 and 1.72 bar. It can be seen that there is increased pressure towards the reactor wall; maximum pressure is confined towards the rector wall over the top to bottom. The reactor model also accounts for maximum pressure build up towards the bottom as the shape is converging towards the grate.

Eddy viscosity is the ratio of average shear stress to the vertical gradient of velocity. It can be inferred from Figure 10 that contour showing the variation of eddy viscosity is dominated from the biomass feed inlet. The shear stress towards the walls is maximum due to the maximum pressure formed and reactor design also plays a vital role in the increased eddy viscosity. The streamlines of eddy viscosity gradient and pressure variation at 500 and 150 points in Figures 12 and 13 clearly shows the fluid (air) flow pattern inside the reactor in both forward and backward direction. From Figure 14, the maximum air density contour is observed. The yellow bubble shows the available air inside in limited quantities. The available air density is reduced on approaching the pyrolytic temperature. Only little air is required during the initial stages of pyrolysis (combustion). The method adopted here was slow pyrolysis hence the yield efficiency is lowered compared to fast pyrolysis that delivers $60-70 \%$ yield efficiency. Pyrolytic process undergoing for the time step size 2000 is simulated to get the results for 20 seconds. Process inside the reactor shown for the parameters studied.

\section{CONCLUSION}

The density, yield efficiency, flash point and fire point of the bio oil extracted from rice straw is calculated. A quantity of $63 \mathrm{ml}$ bio oil having a mass of $59.24 \mathrm{~g}$ is extracted from $1 \mathrm{~kg}$ rice straw. Hence, for extracting 1 litre of bio oil, $15.87 \mathrm{~kg}$ of rice straw is required. The yield efficiency is lower as the method used here is slow pyro- lysis. A two dimensional model to simulate the pyrolysis method of gas production is done in ANSYS 14.5. The developed model is used to analyse the effect of turbulence in the fluid. From the simulation results it was found that the effect of turbulence cannot be neglected in the modelling of fixed-bed reactor. Moreover, the reactor design needs modification for better process optimisation. The model is used to analyse the temperature distribution, pressure variation, eddy viscosity and density over the reactor and properties are studied. The advancements in Liquefaction and pyrolysis method can improve the yield efficiency of bio-oil, moreover further experiments on the bio-oil produced can make it as possible alternative in future for engine applications.

\section{REFERENCES}

Anil, M., Rupesh, S., Muraleedharan, A. (2016). Performance evaluation of fluidised bed biomass gasifier using CFD. Energy Procedia 90: 154-162.

ASTM E17551-01 (2015). Standard test method for ash in biomass. West Conshohocken, PA: ASTM International.

ASTM E872-82 (2013). Standard test method for volatile matter in the analysis of particulate wood fuels. West Conshohocken, PA: ASTM International.

ASTM E1756-08 (2015). Standard test method determination of total solids in biomass. West Conshohocken, PA: ASTM International.

Bridgwater, A.V., Meier, D., Radlein, D. (1999). An overview of fast pyrolysis of biomass. Organic Geochemistry. 30: 1479-1493.

Demirbas, A. (2007). The influence of temperature on the yields of compounds existing in bio-oils obtained from biomass samples via pyrolysis. Fuel Processing Technology 88: 591-597.

Demirbas, A., Gullu, D. (1998). Acetic acid, methanol and acetone from lignocellosics by pyrolysis. Energy Edu. Sci. Technol. 1: 111-115.

Bouvier, M.G., Maugendre, S. (1988). Wood liquefaction an overview. Applied Energy 30: 85-98.

French, R., Czernik, S. (2010). Catalytic pyrolysis of biomass for biofuels production. Fuel Processing Technology 91: 25-32.

Qi, Z., Jie, C., Tiejun, W., Ying, W. (2007). Review of biomass pyrolysis oil properties and upgrading research. Energy Conservation and M anagement 48: 87-92.

Ucar, S., Karago, S. (2009). The slow pyrolysis of pomegranate seeds: The effect of temperature on the product yields and bio-oil properties. J. Anal. Appl. Pyrolysis 84: 151-156.

Wu, L., Guo, S., Wang, C., Yang, Z. (2009). Production of alkanes (C7-C29) from different part of poplar tree via direct deoxy-liquefaction. Bio resource Technology 100: 2069-2076. 